\title{
Comparison of Ultrasound-Guided Drainage with Other Available Treatment Modalities for, Treatment of Tubo-Ovarian Abscess
}

\author{
Edip AYDIN, ${ }^{a}$ \\ (1) Nurullah PEKER, ${ }^{a}$ \\ (D) M. Hanifi BADEMKIRAN, ${ }^{a}$ \\ (1) M. Sait IÇEN, ${ }^{b}$ \\ (1) Talip GÜL ${ }^{b}$
}

aDepartment of Obstetrics and Gynecology, Universtity of Health Sciences

Gazi Yaşargil Training and

Research Hospital,

${ }^{b}$ Department of Obstetrics and Gynecology, Dicle University Faculty of Medicine,

Diyarbakır

Received: 24.12.2017

Received in revised form: 28.02 .2018

Accepted: 19.03 .2018

Available online: 10.04 .2018

\section{Correspondence:}

M. Hanifi BADEMKIRAN

Universtity of Health Sciences

Gazi Yaşargil Training and

Research Hospital,

Department of Obstetrics and Gynecology,

Diyarbakır, TURKEY

hanifibademkiran@hotmail.com

\begin{abstract}
Objective: The present study aimed at the retrospective evaluation of the medical records of patients treated for tubo-ovarian abscess (TOA) at our clinic and investigation of the efficacy of USG-guided drainage compared with that of other available treatment modalities. Material and Methods: Medical records of 100 patients with TOA, who were treated and followed up at the Department of Gynecology and Obstetrics, School of Medicine, Dicle University between January 2009 and April 2015, were reviewed retrospectively. Details such as demographic data, risk factors, clinical and laboratory findings, treatment modalities used, and complications observed were recorded for each patient. Results: The mean age of the patients was $36.46 \pm 11.6$ years. Of the 100 patients, 10 were menopausal women. Pelvic pain was the most common complaint in all patients $(100 \%)$. The history of intrauterine or intra-abdominal intervention within six months was the most common risk factor (60.5\% patients) for the development of TOA. Of the patients, $25 \%$ reported fever $\left(\geq 38{ }^{\circ} \mathrm{C}\right), 55 \%$ had leukocytosis, $85 \%$ had high sedimentation rate, and $92 \%$ had high CRP levels. The development of leukocytosis was not observed to be associated with the treatment modality used ( $\mathrm{p}>0.05$ ). Of the patients, $38 \%$ underwent only medical treatment, $47 \%$ underwent medical treatment followed by surgery, and $15 \%$ underwent medical treatment followed by USGguided drainage. All 34 (72.3\%) patients who had undergone surgical treatment required fertilitypreserving surgery. Intraoperative bowel injury (6.3\% patients) and wound site infection $(8.5 \%$ patients) were among the common complications reported in patients undergoing surgical treatment. The mean duration of hospital stay was $7.9 \pm 6$ days. The longest mean duration of hospital stay $(10.5 \pm 3.9$ days) was observed in the patients who had undergone USG-guided drainage. Conclusion: Broad-spectrum antibiotic therapy, the first step of treatment in patients with TOA, increases the size of abscess. In addition, a significant number of patients with bilateral abscesses require additional intervention (surgery). Our findings suggest that USG-guided drainage should be considered only in patients not responding to medical treatment and not consenting to undergo surgical treatment.
\end{abstract}

Keywords: Tubo-ovarian abscess; medical treatment; surgical treatment; USG-guided drainage

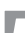
ubo-ovarian abscess (TOA) is the eventual outcome of acute pelvic inflammatory disease (PID) and is characterized by the formation of an inflammatory mass in the pelvic region. This infection may later progress to the intestines, uterus, omentum, and bladder. ${ }^{1}$ Every year, one million women in the United State receive treatment for PID, of which approximately 200,000 women are admitted to hospitals. ${ }^{2}$

Although antibiotic therapy is an accepted treatment for TOA, it does not always provide positive results because of the impaired permeability of antibiotics through the abscess wall. Surgical treatment is still required in $25 \%$ cases after antibiotic therapy. ${ }^{3}$ Therefore, removal of the abscess or adnexa through laparotomy or laparoscopy is recommended. ${ }^{4}$ 
USG-guided drainage is suitable for patients failing to completely respond to antibiotic therapy. Several studies have reported a response rate of $70 \%-100 \%$ in patients undergoing USG-guided drainage for treatment of TOA. ${ }^{5}$ Generally, surgical treatment is performed when minimally invasive drainage is not possible (because of a multilocular mass, poor abscess location, or inadequate experience). The present study retrospectively evaluated the medical records of patients undergoing treatment on TOA at our clinic and compared the importance of USG-guided drainage with other treatment modalities used.

\section{MATERIAL AND METHODS}

\section{HISTORY OF PATIENTS SELECTED FOR THE STUDY}

We retrospectively examined the medical records of 100 patients with TOA following up at the Department of Gynecology and Obstetrics, Faculty of Medicine, Dicle University, between January 2009 and April 2015. This study was performed in accordance with the principles of the Declaration of Helsinki, 2008. The study protocol was approved by the institutional review board and informed consent was obtained from the patients participating in the study. The diagnosis of TOA was based on classical PID findings including abdominal pain, cervical and adnexal tenderness on vaginal examination, and at least one of the minor criteria: fever $\left(38{ }^{\circ} \mathrm{C}\right.$ or more), leukocyte count higher than $10,000 / \mathrm{mL}$, increased erythrocyte sedimentation rate, increased CRP levels, and the presence of a sonographic mass (a complex cystic mass with irregular walls, partitions, internal echoes, and no peristalsis). The initial medical treatment for all the patients with TOA involved antibiotic treatment course with $2 \mathrm{~g}$ ampicillin every $6 \mathrm{~h}$ and a loading dose of $2 \mathrm{mg} / \mathrm{kg}$ gentamicin, followed by $1.5 \mathrm{mg} / \mathrm{kg}$ gentamicin every $8 \mathrm{~h}$ and $900 \mathrm{mg}$ clindamycin every $8 \mathrm{~h}$. These patients were given antibiotics intravenously till observation of a significant reduction in pain and tenderness, abatement of fever, normalization of leukocytosis, and stability or decrease in the size of the mass as visualized in imaging studies. The antibiotics were transitioned to oral route till complete resolution of the TOA was observed on repeat imaging. The patients who had recovered completely $(n=38)$ were considered to be responsive to the medical treatment. The remaining patients $(n=62)$ who did not recover after the medical treatment (antibiotic therapy), or those displaying an increase in fever, elevated CRP levels, and increased leukocyte counts, were considered to be unresponsive to the medical treatment. These patients had undergone surgical treatment or USGguided drainage for treatment of TOA. The time periods between the medical treatment and surgery or USG-guided drainage were recorded for patients undergoing either of the procedures. USG-guided drainage procedure in TOA patients was performed by trans-abdominal route. If the TOAs were ruptured, multi-loculated, or difficult to access via USG-guided drainage, laparoscopy or laparotomy was performed. Data on the socio-demographic characteristics, menopausal status, duration of IUD use, history of pelvic surgical procedures, pelvic USG findings, clinical and laboratory outcomes, operation types, and complications were collected from the patient files.

\section{STATISTICAL ANALYSIS}

Statistical analysis was performed using SPSS version 21.0 for Windows (SPSS Amos). Measured variables were expressed as mean \pm standard deviation, and categorical variables were expressed as numbers and percentages (\%). KolmogorovSmirnov test was used to determine whether study data were normally distributed. Chi-square $\left(\chi^{2}\right)$ test was used to compare qualitative variables determined according to cut-off values. The study hypotheses were bi-directional and $\mathrm{p}$-value $<0.05$ was considered statistically significant.

\section{RESULTS}

The mean age of the study patients with TOA at the time of the treatment was $36.46 \pm 11.6$ years. Of 100 patients, $73 \%$ were multipara and $5 \%$ were nullipara. Moreover, 9 patients were virgins and 10 patients were post-menopausal.

The history of use of intrauterine device (IUD) and PID are risk factors for TOA. In the present study, 7\% patients had a history of IUD use and 
$29 \%$ patients had a history of PID. The patients with TOA frequently complained of high fever, pelvic pain, and vaginal discharge. In the present study, all the patients with TOA (100\%) experienced pelvic pain. In addition, 19\% patients also reported high fever and 27\% patients complained of vaginal discharge.

Antibiotic therapy was the first line of treatment for TOA. Assessment of treatment modalities used in the present study indicated that all the patients had undergone medical treatment with antibiotics. However, only $38 \%$ of the patients responded to medical treatment alone. Of the remaining patients who did not respond to the medical treatment, $47 \%$ patients were operated surgically and $15 \%$ patients were subjected to USGguided drainage (Diagram 1).

At the time of follow-up in the first days of hospitalization for TOA patients, 25 patients had a body temperature above $38{ }^{\circ} \mathrm{C}$ and 12 of these 25 patients required surgical treatment.

The mean leukocyte counts and CRP levels in patients undergoing medical treatment were $11,850 / \mathrm{mm}^{3}$ and $11.1 \mathrm{mg} / \mathrm{dL}$, respectively, while those in patients undergoing surgical treatment were $13,780 / \mathrm{mm}^{3}$ and $14.1 \mathrm{mg} / \mathrm{dL}$, respectively, and those in patients undergoing USG-guided drainage were $14,870 / \mathrm{mm}^{3}$ and $16.2 \mathrm{mg} / \mathrm{dL}$, respectively.

The evaluation of the risk factors of TOA showed that intra-abdominal intervention was a risk factor in 62 patients and intrauterine intervention or operative vaginal birth was a risk factor in 14 patients. Of the 62 patients having intra-abdominal intervention as the risk factor, $60.5 \%$ and $39.5 \%$ patients had undergone an intra-abdominal surgery within and over 6 months before the development of TOA, respectively. Cesarean section was the most common surgical procedure (36\% patients). Among the patients who had undergone an intra-abdominal or intrauterine intervention, $40.8 \%$ received medical treatment, $43.4 \%$ were subjected to surgical treatment, and $15.8 \%$ underwent USG-guided drainage (Table 1).
All the study patients (100\%) were observed to have received a combination of clindamycin (900 mg $3 \times 1 /$ day $)+$ gentamicin (120 mg $1 \times 1 /$ day $)$ + ampicillin $(4 \times 1 \mathrm{~g} /$ day $)$. This medical treatment was also continued after the surgical treatment or USG-guided drainage. The analysis of the types of surgical methods used showed that seven out of 47 patients had undergone laparoscopy, while the remaining 40 patients had undergone laparotomy. USG-guided drainage was performed on 15 patients who had undergone surgical treatment, 14 patients who had undergone salpingo-oophorectomy (SO), three patients who had undergone salpingostomy, one patient who had undergone hysterectomy $(\mathrm{TAH})+$ salpingectomy, two patients who had undergone TAH + unilateral SO (USO), and ten patients who were subjected to TAH + bilateral SO (BSO). The analysis of postoperative complications in patients undergoing surgical treatment indicated that $6.3 \%$ patients developed an intra-bowel injury, which was corrected by performing a general intraoperative surgery, and $8.5 \%$ patients developed wound infection (Diagram 1).

The mean duration between the initiation of medical treatment and surgical treatment was 2.1 \pm 1.5 days and that between the initiation of medical treatment and USG-guided drainage was 6.1 days. The study patients stayed at the hospital for $7.9 \pm 6$ days on average. The mean duration of hospital stay of patients undergoing the medical treatment was $6.9 \pm 2.8$ days, that of patients undergoing the surgical treatment was $8.0 \pm 8.03$ days, and that of patients undergoing USG-guided drainage was $10.5 \pm 3.9$ days.

\section{DISCUSSION}

In women, TOA often develops during the reproductive period. In the present study, the average age of patients with TOA compared with that reported in previous studies was $36.46 \pm 11.6$ years. ${ }^{6,7}$ An analysis of the history of IUD use and PID in patients with TOA showed that $29 \%$ patients had a history of PID and 7\% had a history of IUD use. However, the percentage of patients with a history of IUD use was lower than that reported in previous studies. This indicated a low level of awareness 


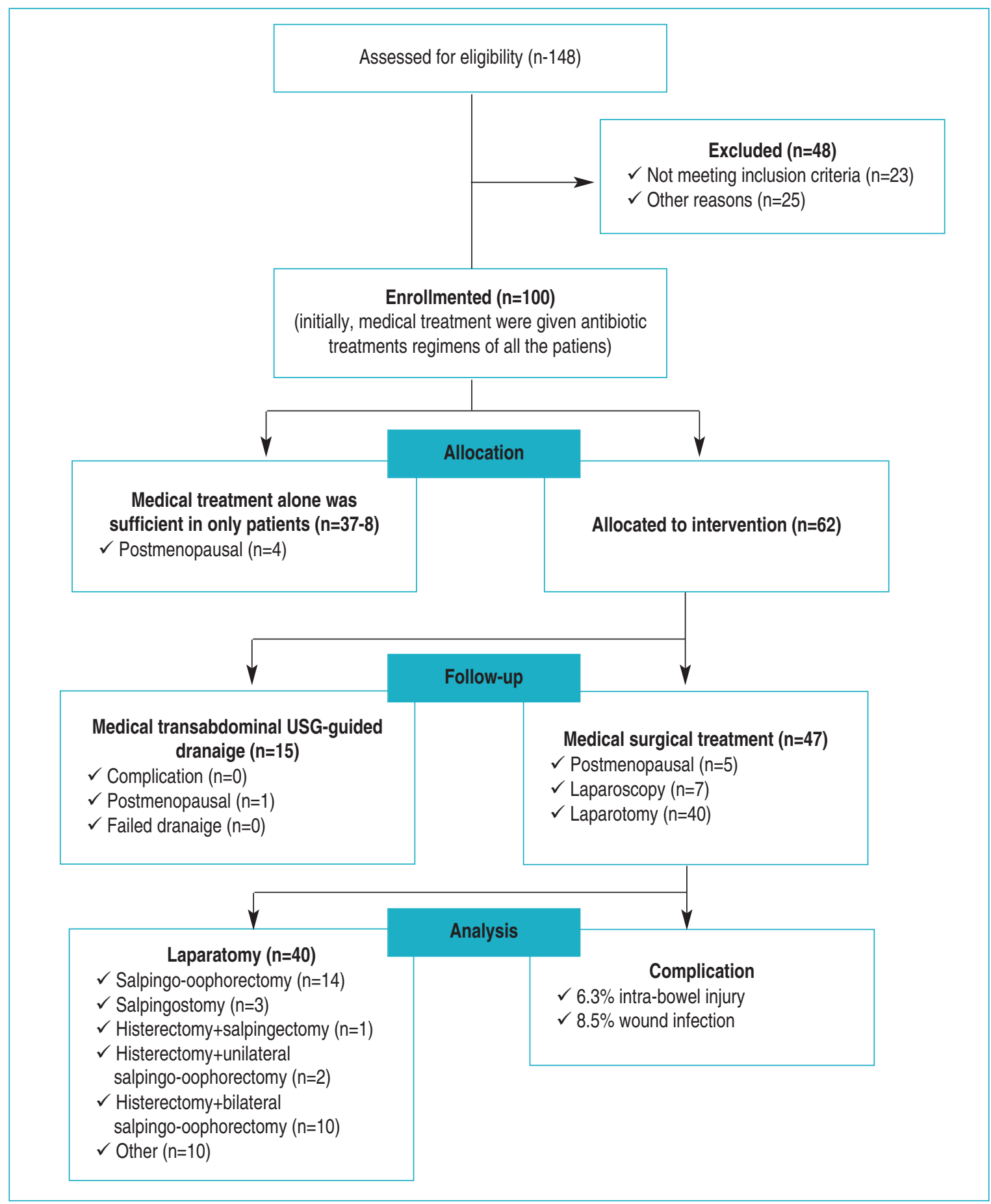

DIAGRAM 1: Flow diagram of TOA patients.

literacy, increased desire for conception, and lesser use of contraceptives among women living in this region. ${ }^{6,8}$

Pelvic pain and high fever are the most common complaints of patients with TOA. ${ }^{9-11}$ In the present study, all patients with TOA had pelvic pain, of which $19 \%$ also had a fever. These findings are consistent with those reported in the previous studies. Previous studies also indicated that high fever was not specifically associated with TOA. ${ }^{12,13}$ 
TABLE 1: Comparison of the treatment modalities with respect to body temperature and the diameter of TOA and the distribution of the treatment modalities according to the history of intra-abdominal or intrauterine intervention.

\begin{tabular}{|c|c|c|c|c|c|c|}
\hline \multirow{2}{*}{\multicolumn{2}{|c|}{ The highest measured fever value }} & \multicolumn{3}{|c|}{ Treatment modalities } & \multirow[b]{2}{*}{ Total } & \multirow[b]{2}{*}{$P$ value } \\
\hline & & Medical Treatment & Surgical Treatment & USG-guided drainage & & \\
\hline \multicolumn{2}{|l|}{$<38^{\circ} \mathrm{C}$} & 29 & 35 & 11 & 75 & \multirow{2}{*}{0.096} \\
\hline \multicolumn{2}{|l|}{$\geq 38^{\circ} \mathrm{C}$} & 9 & 12 & 4 & 25 & \\
\hline \multirow{2}{*}{$\begin{array}{l}\text { History of intra-abdominal or } \\
\text { intrauterine intervention }\end{array}$} & available & 31 & 33 & 12 & 76 & \\
\hline & Absent & 7 & 14 & 3 & 24 & \\
\hline \multirow[t]{6}{*}{ Diameter of TOA } & $\leq 6 \mathrm{~cm}$ & $45.2 \%$ & $35.7 \%$ & $19.1 \%$ & & \multirow{6}{*}{0.153} \\
\hline & $\geq 6 \mathrm{~cm}$ & $32.8 \%$ & $55.2 \%$ & $12 \%$ & & \\
\hline & $\leq 7 \mathrm{~cm}$ & $41.8 \%$ & $41.8 \%$ & $16.4 \%$ & & \\
\hline & $\geq 7 \mathrm{~cm}$ & $30.3 \%$ & $57.5 \%$ & $12.3 \%$ & & \\
\hline & $\leq 8 \mathrm{~cm}$ & $41.1 \%$ & $42.5 \%$ & $16.4 \%$ & & \\
\hline & $\geq 8 \mathrm{~cm}$ & $29.6 \%$ & $59.3 \%$ & $11.1 \%$ & & \\
\hline
\end{tabular}

The highest reported body temperature in patients with TOA was $37.6{ }^{\circ} \mathrm{C} \pm 0.6{ }^{\circ} \mathrm{C}$ in a study by Karakulak et al., and $37.24^{\circ} \mathrm{C} \pm 0.788^{\circ} \mathrm{C}$ in a study by Topçu et al..$^{6,14}$ In the present study, the average body temperature in patients with TOA was 37.4 ${ }^{\circ} \mathrm{C} \pm 0.77^{\circ} \mathrm{C}$, which was similar to that reported in the previous studies.

Some studies had compared mean body temperatures corresponding to the treatment modalities used. Topçu et al. reported that mean body temperatures of patients undergoing medical and surgical treatments were $37.24{ }^{\circ} \mathrm{C} \pm 0.788{ }^{\circ} \mathrm{C}$ and $37.18^{\circ} \mathrm{C} \pm 0.739^{\circ} \mathrm{C}$, respectively. Mizushima et al. reported that mean body temperatures of patients undergoing medical and surgical treatments were $37.6{ }^{\circ} \mathrm{C} \pm 0.85{ }^{\circ} \mathrm{C}$ and $37.5^{\circ} \mathrm{C} \quad \pm 0.9{ }^{\circ} \mathrm{C}$, respectively. ${ }^{14,15}$ In the present study, the mean body temperature of patients undergoing the medical treatment was $37.3^{\circ} \mathrm{C} \pm 0.7^{\circ} \mathrm{C}$, that of patients undergoing the surgical treatment was $37.4{ }^{\circ} \mathrm{C} \pm 0.8$ ${ }^{\circ} \mathrm{C}$, and that of patients undergoing USG-guided drainage was $37.6^{\circ} \mathrm{C} \pm 0.61{ }^{\circ} \mathrm{C}$. In addition, we observed that the mean body temperature of patients undergoing the surgical treatment was not only different from that reported in previous studies but was also higher than that of patients undergoing the medical treatment. However, patients undergoing USG-guided drainage had the highest mean body temperature. This could be because the study patients who had undergone USG-guided drainage were previously admitted to other centers before being referred to our department, and may probably have received late treatment.

Some studies compared the differences in laboratory findings of patients depending on the treatment modalities used. Previous studies reported leukocyte counts and CRP levels of 11.500 $16.000 / \mathrm{mm}^{3}$ and $7.6-14 \mathrm{mg} / \mathrm{dL}$, respectively, in patients undergoing medical treatment, and $14000-16700 / \mathrm{mm}^{3}$ and $16.1-53.8 \mathrm{mg} / \mathrm{dL}$, respectively, in patients undergoing surgical treatment, indicating that leukocyte counts and CRP levels of patients undergoing surgical treatment were higher than those of patients undergoing medical treatment. ${ }^{7,12,14-16}$ In the present study, the mean leukocyte count and CRP level of patients undergoing medical treatment were $11.850 / \mathrm{mm}^{3}$ and 11.1 $\mathrm{mg} / \mathrm{dL}$, respectively, while those of patients undergoing surgical treatment were $13.780 / \mathrm{mm}^{3}$ and 14.1 $\mathrm{mg} / \mathrm{dL}$, respectively, and those of patients undergoing USG-guided drainage were $14.870 / \mathrm{mm}^{3}$ and $16.2 \mathrm{mg} / \mathrm{dL}$, respectively. These findings indicated that leucocyte counts and CRP levels of patients undergoing surgical treatment were higher than those of patients undergoing medical treatment, which was consistent with that reported in previ- 
ous studies. The elevation of CRP levels plays a decisive role in determining the type of medical and surgical treatments to be used. We also observed that patients who had undergone USG-guided drainage had the highest mean leukocyte count and CRP level, suggesting that USG-guided drainage could be used as an alternative to surgical treatment. However, confirmation of this requires a larger sample size than that used in this study.

Kaplan et al. reported that 19\% patients with TOA had previously undergone an intra-abdominal intervention. ${ }^{9}$ In the present study, $62 \%$ patients had previously undergone an intra-abdominal intervention. This difference may be because our hospital is a specialized one, and patients from lower-level hospitals are referred to us if they do not respond to treatment.

Previous studies reported that the history of surgical treatment within six months back increased the risk of TOA formation. ${ }^{6,7}$ In the present study, $46 \%$ patients had undergone a surgery within six months and 30\% patients had undergone a surgery over six months before TOA development, which was consistent with that reported in previous studies.

Some studies analyzed the diameters of abscess by use of imaging techniques. Karakulak et al. reported a mean abscess diameter of $6.0 \pm 3.1 \mathrm{~cm}, \mathrm{Ka}$ plan et al. reported a mean abscess diameter of 7.1 $\pm 2.7 \mathrm{~cm}$, and Güngördük et al. reported a mean abscess diameter of $6.4 \pm 2.9 \mathrm{~cm} .{ }^{6,9,12}$ In the present study, the mean abscess size $(7.2 \pm 2 \mathrm{~cm})$ was similar to that reported in previous studies. Some studies compared abscess sizes of patients with TOA depending on the treatment modalities used. Topçu et al. reported the mean abscess sizes of patients undergoing surgical and medical treatments to be $4.50 \pm 1.71$ and $6.38 \pm 2.18 \mathrm{~cm}$, respectively, while Mizushima et al. reported sizes of $3.9 \pm 1.3$ and 6.6 $\pm 1.5 \mathrm{~cm}$, respectively, Kuru et al. reported sizes of $5.3 \pm 0.1$ and $6.1 \pm 0.1 \mathrm{~cm}$, respectively, and Soydinç et al. reported sizes of $4.75 \pm 0.98$ and 6.18 $\pm 2.12 \mathrm{~cm}$, respectively. ${ }^{14-17}$ The mean abscess sizes of patients undergoing the surgical and medical treatments in our study were $6.6 \pm 2.6$ and $8 \pm 3.3$ cm, respectively. Previous studies demonstrated that surgical cure rate was higher than medical cure rate in patients, when the abscess sizes was based on 6,7 , and $8 \mathrm{~cm} ., 12,14,18$ The present study also showed that the surgical cure rate was higher than the medical cure rate in patients, which the abscess sizes was based on $6 \mathrm{~cm}(55.2 \%), 7 \mathrm{~cm}$ (57.5\%), and $8 \mathrm{~cm}(59.3 \%)$.

In larger case studies(TOA), only $70 \%$ patients underwent medical treatment. ${ }^{19,20,21}$ Laparoscopy is the gold standard for diagnosis and treatment of TOA. ${ }^{22}$ However, complications may occur in patients undergoing laparoscopy, because of adhesion depending on previous surgical treatments. When planning a surgical treatment, it is very important to consider the age of the patient, requirement of fertility and spread of the abscess. Conservative treatment can be considered depending on the age and fertility status of a patient, although USO, BSO, or TAH + BSO may be performed on older, infertile patients. ${ }^{9}$

Güngördük et al. reported that $74.3 \%$ patients required only medical treatment and that $25.7 \%$ patients who did not respond to the medical treatment required surgical treatment. Similarly, Kuo et al. reported that medical treatment alone was sufficient in $84 \%$ patients and that surgical treatment was required in $16 \%$ patients who did not respond to the medical treatment. ${ }^{7}$ In the present study, medical treatment alone was sufficient in only $38 \%$ patients and surgical treatment and USG-guided drainage were, respectively, required in $47 \%$ and $15 \%$ patients who did not respond to the medical treatment. The possible reason for the low response rate to medical treatment alone at our center could be the referral of patients not responding to medical treatment at the other centers. These findings are consistent with those of previous studies and suggest that USG-guided drainage is an alternative to surgical treatment in some patients.

Arici et al. reported that $46.1 \%$ patients who wanted to maintain fertility underwent an organpreserving surgery (abscess drainage), while 53.9\% patients who did not want to maintain fertility underwent resection surgery. Laparoscopy was per- 
formed in $21.1 \%$ patients, while laparotomy was performed in $79.9 \%$ patients. ${ }^{16}$ Moreover, $81.9 \%$ of the patients undergoing laparoscopy required abscess drainage, $63.4 \%$ patients undergoing laparotomy required resection surgery, and $36.6 \%$ patients required organ-preservation surgery. ${ }^{10}$ Kuru et al. reported that a considerable number of patients (32\%) with advanced age underwent resection surgery (TAH $+\mathrm{BSO}) \cdot{ }^{16}$ In the present study, the analysis of the types of surgical treatments showed that $14.8 \%$ patients requiring surgical treatment underwent laparoscopy and 85.2\% patients requiring surgical treatment underwent laparotomy. Abscess drainage was performed in all the patients operated using laparoscopy, 25\% patients using laparotomy, 35\% patients using SO, $7.5 \%$ patients using salpingectomy alone, $2.5 \%$ patients using $\mathrm{TAH}+$ salpingectomy, $5 \%$ patients using TAH + USO, and 25\% who had undergone $\mathrm{TAH}+\mathrm{BSO}$. Resection surgery was performed in $32.5 \%$ patients who had undergone laparotomy.

Previous studies reported the potential occurrence of bladder, bowel, and ureter injuries during TOA surgery and development of wound infection and atelectasis during the postoperative period. ${ }^{6,12} \mathrm{In}$ the present study, intestinal injury and wound infection were observed in $6.3 \%$ and $8.5 \%$ patients, respectively, who had undergone surgical treatment.

Surgical treatment may be performed within 48-72 $\mathrm{h}$ after medical treatment in case of the exacerbation of clinical symptoms, persistence of fever and leukocytosis, and no decrease in abscess diameter. Kaplan et al. reported that the duration between the initiation of medical treatment and surgical treatment was $2.4 \pm 1.3$ days, which is consistent with that observed in the present study (2.1 \pm 1.5 days). ${ }^{15}$ In patients undergoing USG-guided drainage, the mean duration between the initiation of medical treatment and USG-guided drainage was 6.1 days. This difference could be attributed to the desire of patients to maintain fertility and to avoid surgical treatment. However, because no significant reduction was observed in abscess diameter, transabdominal USG-guided drainage was performed as an alternative in patients agreeing to undergo the surgical treatment.
The mean duration of hospitalization in previous studies was nine days. ${ }^{12,16}$ The mean duration of hospitalization in the present study was $7.9 \pm 6$ days. A study by Kuo et al. reported the mean duration of hospitalization for patients undergoing medical treatment alone and for those undergoing medical and surgical treatments to be 7.4 and 10.9 days, respectively, while Gunterdik et al. reported it to be 7.8 and 13.2 days, respectively, and Kuru et al. reported it to be 8.2 and 16.2 days, respectively. ${ }^{7,12,16}$ This indicates that the duration of hospitalization was longer in patients undergoing surgical treatment than those undergoing medical treatment. In the present study, the mean duration of hospitalization was $6.9 \pm 2.8$ days for patients undergoing medical treatment, $8.0 \pm 8.03$ days for patients undergoing surgical treatment, and $10.5 \pm 3$ days for patients undergoing USG-guided drainage, which was similar to that reported in previous studies. Our findings confirmed that the mean duration of hospitalization was longer for patients undergoing surgical treatment than for patients undergoing medical treatment alone. In addition, patients undergoing USG-guided drainage required a longer duration of hospitalization than those undergoing surgical treatment. This could be because of the increased duration between the medical treatment and USG-guided drainage. The decrease in this duration may decrease the duration of hospitalization for patients undergoing USG-guided drainage, compared to that required for patients undergoing the medical treatment.

\section{CONCLUSION}

Treatment of TOA, which is an important condition because of its associated mortality and morbidity, should be selected after considering the age of patients, requirement of fertility, and clinical condition. Medical and surgical treatments should be initiated early for patients with TOA caused by an ovarian function. Moreover, it is important to consider the adverse effects of the treatment modalities on fertility and high morbidity and mortality in untreated patients with a ruptured abscess. USG-guided drainage might be performed as an alternative to surgical treatment, especially in pa- 
tients who wish to receive fertility-preserving treatment and who do not wish to undergo a surgery.

\section{Source of Finance}

During this study, no financial or spiritual support was received neither from any pharmaceutical company that has a direct connection with the research subject, nor from a company that provides or produces medical instruments and materials which may negatively affect the evaluation process of this study.

\section{Conflict of Interest}

No conflicts of interest between the authors and / or family members of the scientific and medical committee members or members of the potential conflicts of interest, counseling, expertise, working conditions, share holding and similar situations in any firm.

\section{Authorship Contributions}

Idea/Concept: Edip Aydın,Nurullah Peker, M. Sait İçen, Talip Gül; Design: Edip Aydın; Control/Supervision: Talip Gül, M.Sait İçen; Data Collection and/or Processing: Edip Aydın; Analysis and/or Interpretation: Edip Aydın, Nurullah Peker, M.Hanifi Bademkıran, İsmail Yılmaz; Literature Review: Edip Aydın, Nurullah Peker, M. Hanifi Bademkıran; Writing the Article: Edip Aydın, Nurullah Peker, M. Hanifi Bademkıran; Critical Review: M. Hanifi Bademkıran; References and Fundings: Edip Aydın.
1. Huang A, Jay MS, Uhler M. Tuboovarian abscess in the adolescent. J Pediatr Adolesc Gynecol 1997;10(2):73-7.

2. Walker CK, Landers DV. Pelvic abscesses: new trends in management. Obstet Gynecol Surv 1991;46(9):615-24.

3. Granberg S, Gjelland K, Ekerhovd E. The management of pelvic abscess. Best Pract Res Clin Obstet Gynecol 2009;23(5):667-8.

4. Krivak TC, Cooksey C, Propst AM. Tuboovarian abscess: diagnosis, medical and surgical management. Compr Ther 2004;30(2): 93-100.

5. Gerzof SG, Johnson WC, Robbins AH, Nabseth DC. Expanded criteria for percutaneous abscess drainage. Arch Surg 1985;120(2): 227-32.

6. Karakulak M, Pala HG, Aydın Y, Saatli B, Guclu S. [Evaluation of the cases with tuboovarian abscesses]. Dokuz Eylül Üniversitesi Tıp Fakultesi Dergisi 2008;22(1): 9-13.

7. Kuo CF, Tsai SY, Liu TC, Lin CC, Liu CP, Lee $\mathrm{CM}$. Clinical characteristics and treatment outcomes of patients with tubo-ovarian abscess at a tertiary care hospital in Northern Taiwan. J Microbiol Immunol Infect 2012;45(1):58-64.

8. Çelik Ç, Gorkemli H, Cicek N, Acar A, Koşuş A, Akyurek C. Evaluation of the cases with tuboovarian abscess. Gynecol Obstet Reprod Med 2002;8(4):219-22.

9. Kaplan Ö, Güney M, Yüksel M. [Tuboovarian

\section{REFERENCES}

abscess, analysis of 61 cases]. S.D.Ü. Tıp Fak Derg 2012;19(2):47-50.

10. Arıcı B, Yumru AE, Salman S, Bozyiğit A, Dinçgez B. [Retrospective analysis of tuboovarian abscess cases operated in our clinic]. Yeni Tıp Dergisi 2013;30(1):62-5.

11. Fabiszewski NL, Sumkin JH, Johns JM. Contemporary radiologic percutaneous abscess drainage in the pelvis. Clin Obstet Gynecol 1993;36(2):445-56.

12. Güngördük $K$, Guzel $E$, Asicioğlu $O$, Yildirim G, Ataser G, Ark C, et al. Experience of tuboovarian abscess in western Turkey. Int J Gynecol Obstet 2014;124(1):45-50.

13. Yeniel Ö, Ulukuş $M$, Yılmaz $A$, Ulukuş $M$, Dinçer Ö. [Clinical and laboratory findings in case of pelvic enflammatory disease complicated by tubo-ovarian abscess]. Turkiye Klinikleri J Gynecol Obst 2003;13(5):379-83.

14. Topçu HO, Kokanalı K, Güzel Al, Tokmak A, Erkılınç $S$, Ümit $C$, et al. Risk factors for adverse clinical outcomes in patients with tuboovarian abscess. J Obstet Gynaecol 2015;35(7):699-702.

15. Mizushima T, Yoshida H, Ohi Y, Ishikawa M, Hirahara F. Evaluating the risk factors for developing resistance to parenteral therapy for tubo-ovarian abscess: a case-control study. J Obstet Gynaecol Res 2013;39(5): 1019-23.

16. Kuru O, Şen S, Saygılı H, Berkman S. Tubo- ovarian abscess: risk factors for failed response to conservative treatment. J Turk Soc Obstet Gynecol 2012;9(2):106-9.

17. Soydinç HE, Evsen MS, Özler A, Sak ME, Turgut A, Görük NY, et al. Tubo-ovarian abscesses: a retrospective analysis of risk factors, clinical features and treatments. Gaziantep Med J 2013;19(2):71-5.

18. Dewitt J, Reining A, Allsworth JE, Peipert JF. Tuboovarian abscesses: is size associated with duration of hospitalization \& complications? Obstet Gynecol Int 2010;2010:847041.

19. Hiller N, Sella T, Lev-Sagi A, Fields S, Lieberman S. Computed tomographic features of tuboovarian abscess. J Reprod Med 2005; 50(3):203-8.

20. Ginsburg DS, Stern JL, Hamod KA, Genadry $\mathrm{R}$, Spence MR. Tubo-ovarian abscess: a retrospective review. Am J Obstet Gynecol 1980;138(7 Pt 2):1055-8.

21. Sweet RL, Schachter J, Landers DV, OhmSmith M, Robbie MO. Treatment of hospitalized patients with acute pelvic inflammatory disease: comparison of cefotetan plus doxycycline and cefoxitin plus doxycycline. Am J Obstet Gynecol 1988;158(3 Pt 2):736-41.

22. Buchweitz O, Malik E, Kressin P, MeyhoeferMalik A, Diedrich K. Laparoscopic management of tubo-ovarian abscesses: retrospective analysis of 60 cases. Surg Endosc 2000; 14(10): 948-50. 